\title{
Remembered duration: Effects of event and sequence complexity
}

\author{
RICHARD A. BLOCK \\ Montana State University, Bozeman, Montana 59717
}

\begin{abstract}
Two experiments investigated the remembered duration of relatively long intervals. In both, subjects viewed two sequences of visual patterns. Then they unexpectedly were asked to make a comparative judgment of duration of the two intervals. In Experiment 1 there was no effect of complexity of the individual patterns on remembered duration. In Experiment 2, however, there was an effect of complexity of the entire sequence, with a complex sequence remembered as longer in duration than a simple sequence. In both experiments there was a positive timeorder error. Several subsequent memory tests were given in an attempt to determine what types of retrieval processes mediate remembered duration. Results were discussed in terms of several current hypotheses, and a contextual change hypothesis was proposed.
\end{abstract}

Questions concerning the experiencing and remembering of duration have been the focus of increasing research efforts. Evidence, especially that obtained in the last decade, seems to support a cognitive, or information processing, approach over an internal clock, or sensory process, approach (for reviews, see Michon, 1972; Ornstein, 1969); but the specific role of cognition in experiencing and remembering duration is unclear. Indeed, there might be several different kinds of duration experiences, with different types of cognitive processes involved in each. For example, different cognitive processes might underlie prospective and retrospective duration experiences (Hicks, Miller, \& Kinsbourne, 1976; James, 1890). Furthermore, different cognitive processes might mediate experiences of duration of short and long intervals (Michon, 1975), as some recent evidence suggests (Hicks \& Miller, 1976). There is also some evidence that duration experiences might be affected by whether or not overt responding to the presented information is required (Vroon, 1970). Regarding these distinctions, the experiments reviewed and reported here are concerned with retrospective experiences of duration of relatively long intervals during which no overt responding is required.

Many hypotheses have been proposed in attempts to explain the various factors that have been found to affect the experience of duration of an interval in retrospect, or "remembered duration," as it will be called here. However, the most comprehensive one is probably Ornstein's (1969) "storage size" hypothesis, which says that remembered duration is a cognitive construction based on the memory "storage size" of the stimulus events that occurred during the interval. Storage size, which presumably is assessed by the person at the time the duration is remembered, is assumed to depend on coding, storage, and retrieval processes. More specifically, it is assumed to increase as the number or complexity of stimulus events occurring during the interval increases. On the problem of actually measuring storage size, Ornstein claimed that "the amount in storage can never really be measured" $(1969$, p. 113). In his experiments, the memory storage size of an interval was inferred from the stimuli presented and the instructions, or "set," provided. However, he did attempt to measure storage size in a few of his experiments, and others (Block, 1974; Kowal, 1976; G. Underwood, 1975) have made similar attempts.

There is little disagreement that presenting more stimulus events during an interval lengthens the remembered duration of the interval (for references and a brief review, see Hicks et al., 1976). It seems reasonable to assume that some aspect of memory storage size increases monotonically with the number of stimulus events. However, Ornstein's (1969) findings that remembered duration also lengthens as a monotonic function of complexity have failed to be replicated in some experiments (Block, 1974, Experiment 2; Hogan, 1975). In addition, some experiments that used a prospective paradigm have also failed to find a significant effect of complexity as predicted by Ornstein's hypothesis (Bobko, Schiffman, Castino, \& Chiappetta, 1977; Kowal, 1976; Smith, 1975; Yeager, 1969).

In every experiment exploring the effect of complexity, one of two different types of complexity manipulations was used. In some experiments, each interval contained a single stimulus event (a visual pattern), and the complexity of the stimulus event or the coding of the event was varied across subjects (Hogan, 1975; Ornstein, 1969, Experiments 2, 8, and 9). In others, each interval contained a sequence of stimulus events, and the complexity (internal structure) of the sequence or the coding of the sequence was varied in some way (Block, 1974, Experiment 2; Bobko et al., 1977; Ornstein, 1969, Experiments 3, 4, and 6; Schiffman \& Bobko, 1974; Smith, 1975; Yeager, 1969). However, to my knowledge no experiment has investigated the effect of presenting a sequence of 
stimulus events while varying only the complexity of individual stimulus events. Furthermore, no experiments have investigated possible effects of complexity of both individual events and sequences of events in a similar paradigm using the same type of stimulus events. The present experiments were designed, therefore, to determine whether the two ways of manipulating complexity have comparable effects on remembered duration. Experiment 1 manipulated the complexity of individual events in a sequence, while holding the complexity (internal structure) of the sequence constant. Experiment 2 manipulated the complexity (internal structure) of a sequence, while holding the complexity of individual events constant. Both used the same general procedure: Subjects were presented two intervals, each of which contained a sequence of visual patterns; then they unexpectedly were asked to give a comparative duration judgment of the two intervals.

Following the duration judgment, several types of memory judgments concerning the presented patterns were requested. The purpose of this testing was to determine whether or not cognitive processes used in certain memory retrieval situations also might be involved in mediating remembered duration. Using this general procedure, Block (1974) concluded that processes involved in both free recall and judgment of number of events probably do not mediate remembered duration, but that processes involved in recognition memory might be involved. In both of the present experiments, subjects were asked to estimate the number of events in the two intervals, and then they were given a recognition memory test that also asked for a judgment of which interval had contained each recognized pattern. The latter type of judgment frequently is called "list discrimination" in verbal learning studies, but will be called "interval discrimination" here. Interval discrimination performance presumably indicates how discriminably different in memory the two subsets of stimuli were at the time of the test.

\section{EXPERIMENT 1}

Effects of the complexity of a stimulus event on remembered duration were found by Ornstein (1969, Experiment 2). The data seemed to indicate that remembered duration lengthens as a function of complexity, but only up to the person's "channel capacity," beyond which increases in complexity have no effect. In contrast, Hogan (1975) used similar materials and found that both the least and the most complex stimuli were remembered as longer in duration than the moderately complex stimuli. In order not to exceed a person's "channel capacity," the present Experiment 1 used stimulus events and an overall presentation rate that seemed to allow for adequate processing of the information. In addition, stimuli

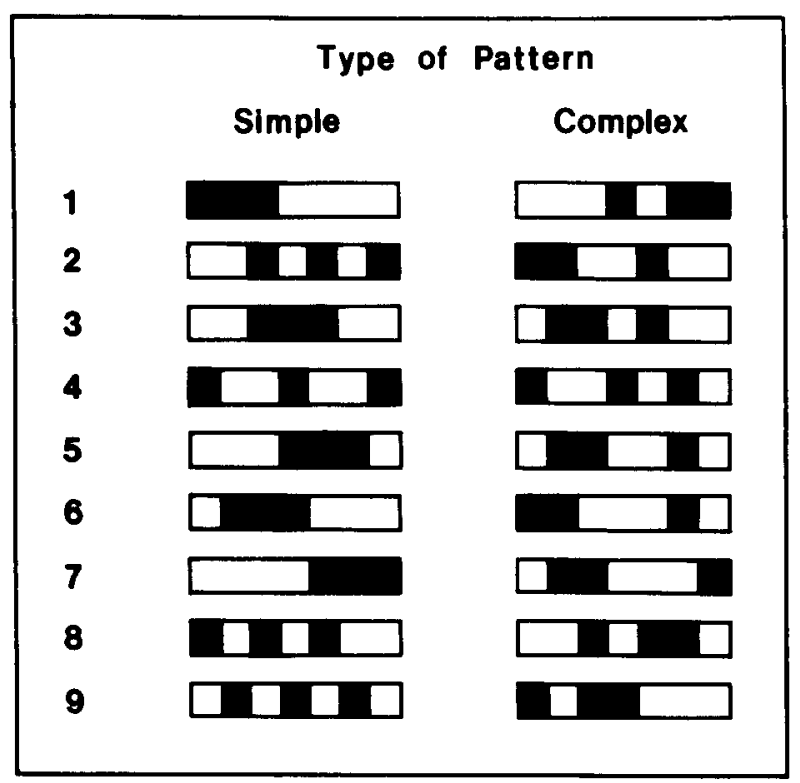

Figure 1. Simple and complex patterns in the order presented during the two intervals in Experiment 1. All patterns appeared on a middle-gray background, with no black border surrounding the rectangular pattern.

were selected in such a way as to avoid a comparison of "overly simple" with "overly complex" stimuli, in Hogan's terms.

\section{Method}

Materials. The stimulus materials were $35-\mathrm{mm}$ slides, each containing 1 pattern of the 35 originally used by Alexander and his colleagues (Alexander \& Carey, 1968; Alexander \& Huggins, 1964). Each pattern consisted of three black and four white squares in a horizontal linear arrangement on a gray background, with no separation between adjacent squares of the same color. Figure 1 shows the two subsets of patterns in the order in which each pattern occurred during each interval. One subset of patterns (hereafter called "simple patterns") consisted of the nine most simple patterns on a composite of the "subjective" and "memorization" scales used by Alexander and Carey.' The other subset (hereafter called "complex patterns") consisted of the nine least simple patterns on a composite of the same two scales. Additional slides of the entire set of 35 patterns were made for the recognition test series. A tape recording containing inaudible signals was used to activate the slide-change mechanism of a carousel projector, which was used to project the slides on a screen. The two intervals were identical in duration, delimited by signals spaced $54 \mathrm{sec}$ apart. The mean exposure duration of individual slides was $6.0 \mathrm{sec}$ (including a blank slide-change interval of $.8 \mathrm{sec}$ ), but was varied randomly between 4.0 and $8.0 \mathrm{sec}$ across slides. A mimeographed sheet was used for the comparative judgment of duration of the two intervals. Instructions were typed at the top. Two lines appeared below, a $50-\mathrm{mm}$ line representing the standard interval above a $100-\mathrm{mm}$ line used to judge the duration of the comparison interval. The lines were labeled "First Series of Slides" and "Second Series of Slides," with labels and instructions reversed on half of the sheets. A mimeographed sheet also was used for the recognition test. Following the ordinal number of the test slide were the words "No" and "Yes" and a blank line for the interval-discrimination judgment.

Subjects. A total of 60 undergraduate students, both male 
and female, participated in the experiment. The data of an additional four participants were discarded because of their failure to follow instructions. All were volunteers obtained from introductory psychology classes, and all received credit for participating.

Procedure. Four to six subjects participated in each session of the experiment. In half of the sessions, all subjects viewed the simple patterns during the first interval (Group SC), while in the other sessions, all subjects viewed the complex patterns first (Group CS). Assignment to the two groups was counterbalanced across sessions. At the start of each session, subjects were told simply that a series of slides would be shown and that they should pay attention to the patterns on the slides so that they would be able to answer some subsequent questions. The first series was presented in a random order. Then subjects were told that a second series of slides would be shown and that the instructions were the same. The second series of slides was shown, also in a random order. It began about $20 \mathrm{sec}$ after the end of the first series. Following the second series, test booklets were distributed. About 2 min were allowed for reading the duration-judgment instructions and making the judgment, which was done by delimiting a line length on the bottom line that corresponded to the apparent length of the comparison interval relative to the standard interval. Half of the subjects judged the first interval relative to the second, while the other half judged the second relative to the first. An equal number of subjects exposed to each presentation order (Groups SC and CS) received each version of the duration-judgment form. Then subjects were asked to estimate the number of patterns that had been presented in each series, and about $1.5 \mathrm{~min}$ was allowed for this task. Instructions for the combined recognition and intervaldiscrimination test said that a series of test patterns would be shown, some of which had been presented earlier and some of which had not. Standard recognition instructions were given, but subjects also were asked to indicate the interval in which each recognized pattern had occurred. About $4 \mathrm{~min}$ after the end of the second interval, the recognition test slides were presented in a random order at a $15-\mathrm{sec}$ rate.

\section{Results and Discussion}

Unless of particular interest, only effects significant beyond the .05 level are described.

Duration judgment. Each duration judgment was measured as the ratio of the apparent duration of the interval containing the complex patterns to that containing the simple patterns (hereafter, the "complex/simple ratio"). Data from subjects judging the first interval were combined with data from those judging the second interval, since there were no significant effects of this variable. Across all subjects, the mean complex/simple ratio was 1.04 . This mean ratio was not significantly different from $1.00[\mathrm{t}(59)=.92$, $\left.\mathrm{SE}_{\overline{\mathrm{x}}}=.039, \mathrm{p}>.05\right]$, and the $95 \%$ confidence interval was between .96 and 1.12. Thus, the experiment had sufficient power to detect an effect of complexity of the magnitude usually reported to be significant, but no effect of stimulus complexity was found. However, the mean complex/simple ratio was greater for Group CS (1.22) than for Group SC $(.86)[F(1,56)=27.3$, $\mathrm{MSe}=.067, \mathrm{p}<.001]$. This type of effect is usually called a "positive time-order error" (Woodrow, 1951). A possible explanation for it will be suggested in the General Discussion.
Judgments of number of patterns. The only significant effect on judgments of number of patterns was a Group by Type of Pattern interaction $[\mathrm{F}(1,58)=38.3$, $\mathrm{MSe}=4.51, \mathrm{p}<.001]$. Simply stated, the first interval was judged to contain more patterns than the second (means of 13.1 and 10.6, respectively). This effect is similar to the positive time-order error in the duration judgment, and similar processes may have been involved in both types of judgments in this experiment.

Recognition memory. Recognition memory was assessed by using a standard correction for guessing, which is simply the probability of a hit minus the probability of a false alarm. ${ }^{2}$ There was no significant effect of type of pattern on recognition memory $[F(1,58)=3.22, \mathrm{MSe}=.036, \mathrm{p}>.05]$. Others (e.g., Clark, 1965) also have found no effect of stimulus complexity on recognition performance. However, performance was significantly greater than zero, or "chance," for the simple patterns, but not for the complex ones (means of .085 and .023 , respectively). As on judgments of number of patterns, there was a Group by Type of Pattern interaction $[\mathrm{F}(1,58)=8.04$, $\mathrm{MSe}=.036, \mathrm{p}<.01]$, with better recognition of patterns presented during the first interval than during the second (means of .103 and .005 , respectively). It is possible that processes similar to those involved in recognition memory may have produced the positive time-order error on the duration judgment.

Interval discrimination. Interval discrimination performance was measured for each subject by counting the number of presented patterns (of each type) that both were recognized and were judged to have occurred in the correct interval and dividing by the total number of presented patterns (of each type) that simply were recognized. There was an effect of type of pattern $[F(1,58)=13.8, \mathrm{MSe}=.041, \mathrm{p}<.001]$, with a greater proportion of recognized simple patterns assigned to the correct interval than recognized complex patterns (means of .750 and .617, respectively). Both types of patterns were assigned to the correct interval with a probability significantly greater than .5 , or "chance." In other words, subjects apparently did remember something about the difference between the two intervals in terms of the type of patterns presented during each. In addition, a significant Group by Type of Pattern interaction $[\mathrm{F}(1,58)=5.24, \mathrm{MSe}=.041$, $\mathrm{p}<.05$ ] indicated that the assignment of a pattern to the correct interval was more likely for those presented during the first interval than for those presented during the second (means of .723 and .643 , respectively).

\section{EXPERIMENT 2}

Two experiments done by Ornstein (1969, Experiments 3 and 4) indicated that remembered duration lengthens as sequence complexity increases. 
Sequences contained several different stimuli, repetitions of which either were massed (simple sequence) or were randomized (complex sequence). The results can be explained by the rather simple notion of habituation. A more interesting experiment (Ornstein, 1969, Experiment 4) seemed to indicate that remembered duration lengthens as the complexity of coding of a presented sequence increases. Subjects who were assumed to be able to code a given sequence in a number of categories ("constructs") remembered its duration as longer than those who were assumed to use fewer categories. However, Block (1974, Experiment 2) found that an interval containing words already organized by category (simple sequence) was remembered as longer in duration than one containing the same words presented in a random order (complex sequence). This finding appears to contradict Ornstein's complexity notion, unless one makes the assumption that a simple sequence might be coded in a more complex way than a complex sequence. The present Experiment 2 was designed to investigate effects of sequence complexity in order to clarify the apparent contradictions of these studies.

\section{Method}

The same set of 35 slides was used in Experiment 2. However, patterns were selected for presentation during one of the two intervals in a different way. Figure 2 shows the two subsets of patterns in the order in which each pattern occurred during each interval. One subset of patterns (hereafter called the "simple sequence") was selected and ordered in such a way that there was a regular, somewhat predictabie sequencing from a given pattern to the subsequent one. The other subset (hereafter called the "complex sequence") was selected in such a way as to have the same mean simplicity rank (17.0 on a composite of the two scales used previously), but the patterns were randomly ordered. All other materials and other essential features of the procedure were the same as in Experiment 1. A total of 64 students, who volunteered as in Experiment 1, participated in the experiment. The data of an additional four participants were discarded because of their failure to follow instructions.

\section{Results and Discussion}

Table 1 shows the mean performance of subjects exposed to each presentation order (Groups SC and CS) on each dependent variable. Only effects significant beyond the .05 level are described.

Duration judgment. Each duration judgment was measured as the ratio of the apparent duration of the

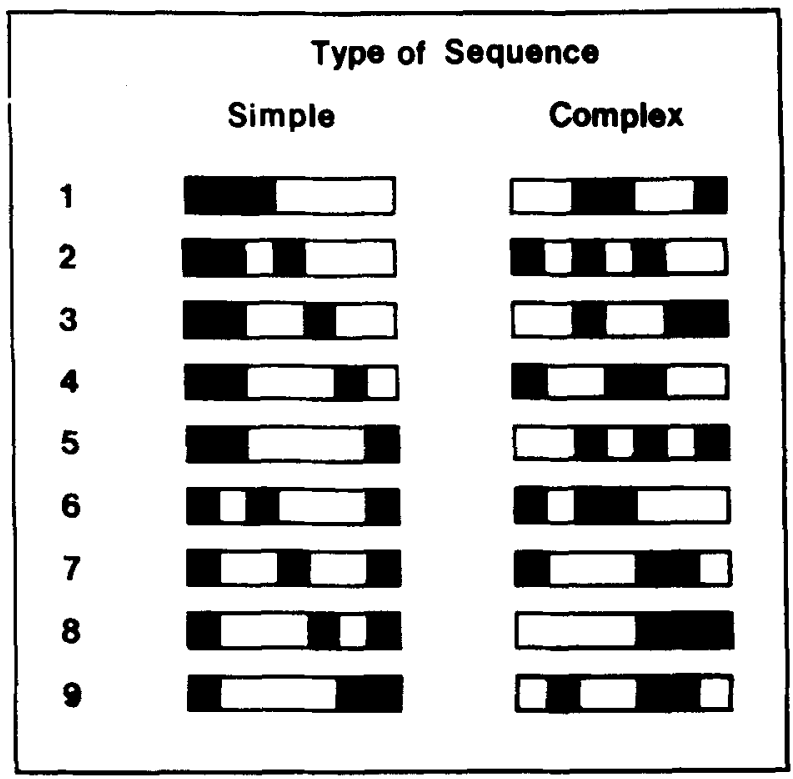

Figure 2. Simple and complex sequences in the order presented during the two intervals in Experiment 2. All patterns appeared on a middle-gray background, with no black border surrounding the rectangular pattern.

interval containing the complex sequence to that containing the simple sequence. Data from subjects judging the first interval were combined with data from those judging the second interval, since there were no significant effects of this variable. Across all subjects, the mean complex/simple ratio was 1.14 , a ratio significantly greater than $1.00[\mathrm{t}(63)=3.55$, $\mathrm{SE} \overline{\mathrm{X}}=.038, \mathrm{p}<.001]$, with a $95 \%$ confidence interval between 1.06 and 1.21. In other words, the complex sequence was remembered as longer in duration than the simple sequence. More will be said about this important finding in the General Discussion. There was also an effect of presentation order on the complex/simple ratio $[\mathrm{F}(1,60)=9.19, \mathrm{MSe}=.082$, $\mathrm{p}<.001]$, with a greater ratio for Group CS than Group SC. This finding replicates the positive timeorder error that was found in Experiment 1.

Judgments of number of pattems. There was an effect of type of sequence on judgments of number of patterns $[\mathrm{F}(1,62)=6.45, \mathrm{MSe}=8.14, \mathrm{p}<.05]$. The mean judgment was greater for the interval containing the complex sequence than for that containing the simple sequence. However, the first interval was not

Table 1

Mean Performance of Each Group (SC and CS) on Each Dependent Variable: Experiment 2

\begin{tabular}{|c|c|c|c|c|c|c|c|c|c|c|c|c|}
\hline \multirow[b]{2}{*}{ Type of Sequence } & \multicolumn{3}{|c|}{ Duration Judgment } & \multicolumn{3}{|c|}{$\begin{array}{c}\text { Judgments of Number } \\
\text { of Patterns }\end{array}$} & \multicolumn{3}{|c|}{$\begin{array}{l}\text { Corrected Recognition } \\
\text { Performance }\end{array}$} & \multicolumn{3}{|c|}{$\begin{array}{c}\text { Interval Discrimination } \\
\text { Performance }\end{array}$} \\
\hline & $\mathrm{SC}$ & $\mathrm{CS}$ & Mean & SC & $\mathrm{CS}$ & Mean & SC & $\mathrm{CS}$ & Mean & SC & $\mathrm{CS}$ & Mean \\
\hline $\begin{array}{l}\text { Complex } \\
\text { Simple } \\
\text { Mean }\end{array}$ & & & & $\begin{array}{l}12.0 \\
11.1 \\
11.5\end{array}$ & $\begin{array}{l}12.8 \\
10.7 \\
11.8\end{array}$ & $\begin{array}{l}12.4 \\
10.9 \\
11.7\end{array}$ & $\begin{array}{l}.171 \\
.282 \\
.227\end{array}$ & $\begin{array}{l}.151 \\
.112 \\
.132\end{array}$ & $\begin{array}{l}.161 \\
.197 \\
.179\end{array}$ & $\begin{array}{l}.648 \\
.770 \\
.709\end{array}$ & $\begin{array}{l}.591 \\
.594 \\
.592\end{array}$ & $\begin{array}{l}.619 \\
.682 \\
.650\end{array}$ \\
\hline Complex/Simple Ratio & 1.03 & 1.25 & 1.14 & & & & & & & & & \\
\hline
\end{tabular}


judged to contain more patterns than the second interval (means of 12.0 and 11.4 , respectively) $(F<1)$. Thus, the positive time-order error in the duration judgment was not reflected in judgments of number of patterns, so processes involved in remembering the number of events in an interval do not mediate remembered duration.

Recognition memory. Corrected recognition memory performance showed no significant effect of type of sequence. Mean performance was significantly greater than zero, or "chance," for patterns from both types of sequences. Thus, processes involved in recognition of individual events out of context do not underlie remembered duration. There was also a significant effect of presentation order $[F(1,62)=4.32, \mathrm{MSe}=.056$, $\mathrm{p}<.05]$, with subjects in Group SC performing considerably better than those in Group CS. Table 1 shows that the major difference between subjects in Groups SC and CS was in recognition of patterns from the simple sequence. One possible explanation is that the initial viewing of a complex (random) sequence of events makes it difficult to perceive the simple (nonrandom) sequence as a regular, orderly progression of patterns.

Interval discrimination. There was no significant effect of type of sequence on interval discrimination performance, although patterns from both the simple and complex sequences were assigned to the correct interval with a probability greater than .5 , or "chance." However, there was a main effect of presentation order $[F(1,62)=4.38, \mathrm{MSe}=.099, \mathrm{p}<.05]$, with subjects in Group SC performing better than those in Group CS. Table 1 shows that the overall pattern of interval discrimination performance was similar to that of recognition performance, with most of the same conclusions applying to both dependent variables.

\section{GENERAL DISCUSSION}

The results of the two experiments reported here suggest that Ornstein's (1969) storage size hypothesis, especially its assumptions about effects of complexity, must be qualified, if not rejected in favor of some more parsimonious alternative. Experiment 1 found no effect on remembered duration of the complexity of individual stimulus events filling an interval. Along with another recent failure to find a predicted monotonic effect of stimulus complexity (Hogan, 1975), this result suggests that further experiments are needed in order to clarify the conditions under which an effect can be obtained. It is possible that the total variation in complexity afforded by the stimuli used in Experiment 1 was not sufficiently great to influence the duration judgment. However, the concept of complexity is not well defined, and it is virtually impossible at present to make comparisons across different kinds of stimuli. Future research might use different kinds of stimuli and at least several levels of complexity in an attempt to determine whether or not the complexity of individual stimulus events does influence remembered duration in a predictable way. Like some previous studies (e.g., Clark, 1965), Experiment 1 found no effect of stimulus complexity on recognition memory. This suggests that data that show an effect of event complexity on remembered duration cannot be explained in terms of Ornstein's storage size hypothesis, which regards memory for individual stimulus events as important.

The finding of Experiment 2 that remembered duration lengthens as sequence complexity is increased seems to support some kind of storage size hypothesis. In addition, the finding suggests that any storage size hypothesis that proposes effects of complexity must emphasize the entire sequence of stored representations of events that occurred during the interval. It is possible that an effect of event complexity will occur only under conditions in which the complexity of an entire sequence of stored representations is affected by the complexity of an individual stimulus event, as in Hogan's (1975) and Ornstein's (1969, Experiment 2) experiments. The recognition memory data of Experiment 2 support the suggested emphasis on the entire sequence of stored representation of events, since individual stimulus events from the complex sequence were not recognized better than those from the simple sequence.

An important finding of both of the present experiments is the positive time-order error, an effect that also has been observed in a few other experiments on remembered duration that used a similar procedure (Harton, 1938; Hogan, 1975). Ornstein's storage size hypothesis can explain the occasional finding of a negative time-order error, in which the second of two intervals is remembered as longer, as caused by "items dropping out of storage" (1969, p. 107). However, there is no apparent way his storage size hypothesis can explain a positive time-order error.

Before proposing a hypothesis that can explain previous and present findings, including the positive time-order error, other possible explanations of the present results must be considered. For example, one hypothesis is that "a reduction in the efficiency in the way events are coded and stored" (Ornstein, 1969, p. 43) tends to lengthen remembered duration. A similar hypothesis is that remembered duration lengthens as a function of the degree of "selectivity of attention" demanded by the information processing task performed during the interval (G. Underwood, 1975; G. Underwood \& Swain, 1973). Both hypotheses seem to be able to explain the effect of sequence complexity found in Experiment 2. G. Underwood's proposal also can explain the positive time-order error by assuming that more attention is paid to the first interval (cf. G. Underwood, 1976, p. 111). However, neither hypothesis can explain the results of an experiment mentioned previously (Block, 1974, 
Experiment 2), which indicate that a sequence of words blocked by category membership is remembered as longer in duration than one in which the same words are randomly ordered. An organized sequence of words is "easier to process" and demands less "selectivity of attention" than an unorganized sequence. In addition, neither hypothesis addresses the question of what retrieval processes are involved in remembering the duration of an interval. Another popular hypothesis (cf. Ornstein, 1969) proposes that remembered duration lengthens as the amount of information processed increases, but this hypothesis encounters similar difficulties.

What is needed is a hypothesis that emphasizes the entire sequence of stored representations of events occurring during the interval, but that also specifies the nature of the memory retrieval processes that mediate remembered duration. One possibility is suggested by Fraisse's (1963) conclusions that duration consists of "successive changes and nothing else" and "psychological duration is composed of psychological changes" (p. 216). His hypothesis that remembered duration is based on the "number of changes observed" (Fraisse, 1963, p. 219), which was the result of an extensive literature review at that time, might be considered and subjected to further experimentation. ${ }^{3}$ To elaborate on his proposal, as well as restate it in more modern terms, what might be important is the remembered amount of change in cognitive context during the interval (cf. Anderson \& Bower, 1972, 1973; Hintzman, Block, \& Summers, 1973). A contextual change hypothesis considers the storage size of both external and internal events, but emphasizes certain attributes of the entire sequence of stored representations, not memory for individual stimulus events. It also can explain a positive time-order error, since certain contextual elements might change very rapidly near the start of an experiment (Hintzman et al., 1973). The notion of "context" is somewhat vague at the present time (cf. B. J. Underwood, 1977). However, recent explorations of a world view called "contextualism" (Jenkins, 1974; Sarbin, 1977), which emphasizes change and the context of events, suggest that future experiments testing the contextual change hypothesis might be productive.

\section{REFERENCES}

Alexander, C., \& Carey, S. Subsymmetries. Perception \& Psychophysics, 1968, 4, 73-77.

Alexander, C., \& Huggins, A. W. F. On changing the way people see. Perceptual and Motor Skills, 1964, 19, 235-253.

ANDERSON, J. R., \& Bower, G. H. Recognition and retrieval processes in free recall. Psychological Review, 1972, 79, 97-123.

ANDERSON, J. R., \& Bower, G. H. Human associative memory. Washington, D.C: Winston, 1973.

BLock, R. A. Memory and the experience of duration in retrospect. Memory \& Cognition, 1974, 2, 153-160.
Bobxo, D. J., Schiffman, H. R., Castino, R. J., \& Chiappetta, W. Contextual effects in duration experience. American Journal of Psychology, 1977, 90, 577-586.

Clark, H. J. Recognition memory for random shapes as a function of complexity, association value, and delay. Journal of Experimental Psychology, 1965, 69, 590-595.

Fraisse, P. The psychology of time. New York: Harper \& Row, 1903.

HaRTON. J. J. The influence of the difficulty of activity on the estimation of time. Journal of Experimental Psychology, 1938, 23. $270-287,428-433$

Hicks, R. E, \& Millek, G. W. Transfer of time judgments as a function of feedback. American Journal of Psychology, 1976, 89, 303-310.

Hicks, R. E., Miller. G. W., \& Kinsbourne, M. Prospective and retrospective judgments of time as a function of amount of information processed. American Journal of Psychology, 1976. 89. $719-730$.

Hintzman, D. L., Block, R. A., \& Summers, J. J. Contextual associations and memory for serial position. Joumal of Experimental Psychology, 1973, 97, 220-229.

Hogan. H. W. Time perception and stimulus preference as a function of stimulus complexity. Journal of Personality and Social Psychology, 1975, 31, 32-35.

JAMES, W. The principles of psychology (Vol. 1). New York: Henry Holt. 1890.

JENKINS, J. J. Remember that old theory of memory? Well, forget it! American Psychologist, 1974, 29, 785-795.

Kowal. K. H. Apparent duration of long meaningful events and meaningless intervals. Memory \& Cognition, 1976, 4, 215-220.

Michon, J. A. Processing of temporal information and the cognitive theory of time experience. In J. T. Fraser, F. C. Haber, \& G. H. Müller (Eds.), The study of time. Heidelberg: Springer-Verlag. 1972.

Michon. J. A. Time experience and memory processes. In J. T. Fraser \& N. Lawrence (Eds.), The study of time II. New York: Springer-Verlag, 1975.

ORNSTEIN, R. E. On the experience of time. Harmondsworth, England: Penguin, 1969.

SARBIN, T. R. Contextualism: A world view for modern psychology. In A. W. Landfield (Ed.), Nebraska symposium on motivation 1976 (Vol. 24). Lincoln: University of Nebraska Press, 1977.

Schiffman, H. R., \& Bobxo, D. J. Effects of stimulus complexity on the perception of brief temporal intervals. Journal of Experimental Psychology, 1974, 103, 156-159.

Sмiтн, M. J. Changes in judgment of duration with different patterns of auditory information for individuals confined to bed. Nursing Research, 1975, 24, 93-98.

UNDERWOOD, B. 1. Temporal codes for memories: Issues and problems. Hillsdale, N.J: Erlbaum, 1977.

UNDERWOOD, G. Attention and the perception of duration during encoding and retrieval. Perception, 1975, 4, 291-296.

UNDERWOOD, G. Attention and memory. Oxford, England: Pergamon, 1976.

UNDERWOOD, G., \& SWAIN, R. A. Selectivity of attention and the perception of duration. Perception, 1973, 2, 101-105.

VROON, P. A. Effects of presented and processed information on duration experience. Acta Psychologica, 1970, 34, 115-121.

Woodrow, H. Time perception. In S. S. Stevens (Ed.), Handbook of experimental psychology. New York: Wiley, 1951.

YEAGER, J. Absolute time estimates as a function of complexity and interruption of melodies. Psychonomic Science, 1969, 15. $177-178$.

\section{NOTES}

1. These two scales seemed more relevant to the present experiment than the others. All five scales, however, were highly correlated. 
2. It was impossible to compute the more generally accepted $\mathrm{d}^{\prime}$ measure of recognition memory, since the probability of a hit was occasionally 1 .

3. In the present experiments, Fraisse's "number of changes observed" might be limited by the actual number of changes in pattern elements from a given pattern to the next. Specifically, if one assumes that the seven positions in each pattern are the elements, one could calculate the mean number of positions changing from white to black and vice versa. It is interesting that these means were nearly identical in Experiment 1 (4.25 for the simple patterns and 4.00 for the complex patterns) but extremely different in Experiment 2 (2.00 for the simple sequence and 3.75 for the complex sequence).

(Received for publication November 22, 1977; accepted December 16.1977.) 